\title{
INDIVIDUAZIONE PRECOCE DI PSEUDOMONAS AERUGINOSA NELL'ESPETTORATO DI PAZIENTI CON FIBROSI CISTICA MEDIANTE PCR
}

\author{
Garlaschi M.L.*, Cariani L.*, Laricchia L.*, Clarizia G.*, \\ Russo P.*, Costantini D. ${ }^{\circ}$, Galbiati S.^, Blasi F.^, Torresani E.* \\ *U.O. Microbiologia, IRCCS Fondazione Policlinico, Mangiagalli e \\ Regina Elena, Milano. \\ ${ }^{\circ}$ Centro Regionale di Riferimento Fibrosi Cistica, \\ Clinica Pediatrica De Marchi, Università di Milano. \\ ^ Lab. Biologia Molecolare, IRCCS Fondazione Policlinico, \\ Mangiagalli e Regina Elena, Milano.
}

Introduzione. L'infezione polmonare da Pseudomonas aeruginosa (PA) nei pazienti con Fibrosi Cistica (FC) provoca un notevole declino della funzionalità respiratoria.

La maggior parte degli AA indica che una precoce terapia antibiotica può prevenire l'instaurarsi di un'infezione cronica da PA, è quindi estremamente importante isolare dall'espettorato, più precocemente possibile $\mathrm{PA}$, così da poter instaurare, ai primi segni di infezione, una terapia antibiotica antipseudomonas.

Scopo del nostro studio è verificare se la ricerca di PA diretta dall'espettorato mediante metodica molecolare in PCR possa contribuire a definire più precocemente, dell'esame colturale, la prima infezione da PA.

Pazienti. Sono stati valutati 66 espettorati di altrettanti pazienti con Fibrosi Cistica, afferenti al Centro di Riferimento Regionale Lombardo.

Metodi. I campioni di espettorato, dopo fluidificazione con sputasol e diluizioni seriali, sono stati seminati, su Agar sangue e Agar Mc Conkey.

Dallo stesso campione utilizzato per l'esame colturale, è stato estratto il DNA genomico batterico mediante estrazione con resine (Extracell, Ditta Biosys ed Estraction Kit Roche) ed è stato amplificato un frammento di DNA specifico del genoma di PA che codifica per una proteina di membrana (gene oprL)

Risultati. Dei 66 pazienti valutati con le due metodiche, 58 sono risultati perfettamente concordanti (11 PA positivi e 47 PA negativi).

Con la metodica colturale sono risultati positivi 11 pazienti; con la metodica molecolare sono risultati positivi 19 pazienti. Degli 8 pazienti risultati positivi solo con la metodica molecolare, 5 erano risultati positivi per PA in modo intermittente all'esame colturale, negli anni precedenti .

Conclusioni. Questo studio preliminare mette in evidenza che il metodo molecolare in PCR è un metodo idoneo per l'evidenziazione precoce di PA.

L'utilizzo quindi di questa metodica potrebbe permettere al clinico di instaurare, nei pazienti infettati con PA, più precocemente la terapia antibiotica antipseudomonas, nel tentativo di ottenerne l'eradicazione. 